\title{
MÉTODOS AUTOMATIZADOS DE DIAGNÓSTICO DE MASTITE EM VACAS LEITEIRAS: UMA REVISÃO
}

Eduardo Mitke Brandão Reis ${ }^{1}$ Marcos Aurélio Lopes ${ }^{2}$

REIS, E. M. B.; LOPES, M. A. Métodos automatizados de diagnóstico de mastite em vacas leiteiras: uma revisão. Arq. Ciênc. Vet. Zool. UNIPAR, Umuarama, v. 17, n. 3, p. 199-208, jul./set. 2014.

RESUMO: A mastite é a infecção mais frequente dos animais destinados à produção de leite e que mais onera a pecuária leiteira. As perdas econômicas são causadas por diversos fatores: medicamentos, morte ou descarte precoce de animais, bem como em laticínios, pela queda na qualidade do produto final. Rotineiramente, quando se pretende verificar a incidência de mastite em vacas leiteiras utilizam-se os métodos convencionais e subjetivos, como a caneca telada e o California Mastitis Test. A automação na pecuária leiteira é uma inovação tecnológica que visa a minimizar os erros de manejo e otimizar os processos dentro da atividade, dentre os quais o diagnóstico precoce de casos subclínicos de mastite. O uso de sensores que utilizam parâmetros objetivos de mensuração tais como: condutividade elétrica, contagem de células somáticas, presença da enzima lactato desidrogenase, mensuração da cor e a homogeneidade podem ser a alternativa para detecção rápida e precisa de mastite em bovinos, especialmente quando se trata de sistemas automatizados, pois o diagnóstico precoce minimiza as perdas econômicas. Diante do exposto, objetivou-se realizar uma revisão bibliográfica sobre os métodos automatizados de detecção de mastite existentes atualmente.

PALAVRAS-CHAVE: Automação. Bovinocultura Leiteira. Inovação Tecnológica. Zootecnia de Precisão.

\section{AUTOMATED DIAGNOSIS METHODS OF MASTITIS IN DAIRY MILK CATTLE: A REVIEW}

\begin{abstract}
The objective of this paper is to perform a bibliographic review on the currently existing automated methods for the detection of mastitis. Usually when one is supposed to verify the incidence of mastitis in dairy cows, conventional and subjective methods, such as the strip cup test and the California Mastitis Test, are used. Automation in dairy farming is a technological innovation aiming to minimize handling errors and to optimize the processes in the activity, among them, the early diagnosis of subclinical mastitis cases, through sensors using objective measuring parameters, such as electric conductivity, somatic cell count, presence of lactate dehydrogenase enzyme, color and homogeneity measurement.
\end{abstract}

KEYWORDS: Automation. Dairy Cattle. Precision Dairy Farming. Technological Innovation.

\section{MÉTODOS AUTOMATIZADOS DE DIAGNOSIS DE MASTITIS EN VACAS LECHERAS: UNA REVISIÓN}

RESUMEN: Mastitis es la infección más frecuente en animales destinados a la producción de leche y más oneroso a la ganadería lechera. Las pérdidas económicas son causadas por diversos factores: medicamentos, muerte o descarte precoz de animales, así como en lacticinios, por la caída en la calidad del producto final. Rutinariamente, cuando se pretende verificar la incidencia de mastitis en vacas lecheras se utilizan los métodos convencionales y subjetivos, como la taza de red y el California Mastitis Test. La automatización en la ganadería lechera es una innovación tecnológica que busca minimizar los errores de manejo y optimizar los procesos dentro de la actividad, entre los cuales el diagnóstico precoz de casos subclínicos de mastitis. El uso de sensores que utilizan parámetros objetivos de mensuración tales como: conductividad eléctrica, conteo de células somáticas, presencia de la enzima lactato deshidrogenasa, mensuración del color y la homogeneidad que pueden ser la alternativa para detección rápida y precisa de mastitis en bovinos, principalmente cuando se trata de sistemas automatizados, pues el diagnóstico precoz minimiza las pérdidas económicas. Delante el expuesto, se ha tenido por objetivo realizar una revisión bibliográfica sobre los métodos automatizados de detección de mastitis existentes actualmente.

PALABRAS CLAVE: Automatización. Ganadería Lechera. Innovación Tecnológica. Zootecnia de Precisión.

\section{Introdução}

O Brasil atingiu, no ano de 2011, a marca de quinto maior produtor mundial de leite, atrás apenas de Estados Unidos, Índia, China e Rússia, e o primeiro da América do Sul. Conta com 1,3 milhões de produtores e produção de 31 bilhões de litros (IBGE, 2012). Não obstante, quando o assunto é produtividade, o Brasil possui baixos índices, com apenas $1.381 \mathrm{~kg}$ de leite/vaca/ano enquanto que países como os Estados Unidos alcançaram produtividade em torno de $9.790 \mathrm{~kg} / \mathrm{vaca} / \mathrm{ano}$, em 2012 (USDA, 2012). Além disso, a pecuária leiteira brasileira é considerada de baixa rentabilidade em função do baixo volume de produção diária, baixaprodutividade por animal e pouco uso de tecnologias (COELHO et al., 2013).

A mastite bovina inflamação da glândula mamária (RADOSTITS et al., 2002), tem sido apontada como a principal doença que afeta os rebanhos leiteiros no mundo, sendo

DOI: https://doi.org/10.25110/arqvet.v17i3.2014.4945

${ }^{1}$ Professor da Universidade Federal do Acre - UFAC, Doutorando em Ciências Veterinárias pela Universidade Federal de Lavras, Centro de Ciências Biológicas e da Natureza. Departamento de Medicina Veterinária. edumitke@hotmail.com.

${ }^{2}$ Professor da Universidade Federal de Lavras, Departamento de Medicina Veterinária. Universidade Federal de Lavras -DMV. Caixa postal 3037, Lavras - MG, 37200-000. 
a doença mais importante em termos de perdas econômicas, e sendo a enfermidade mais difícil de ser controlada (REBHUN, 2000). Segundo Nickerson (2002), os de mastite nas propriedades costumam ser observados tardiamente, sendo percebidos quando há uma queda na produção de leite, altos gastos com o tratamento dos animais doentes, descarte do leite devido a resíduos de antibiótico no leite, descarte de vacas devido à perda de vários tetos pela mastite ou pela cronicidade da doença em determinados animais, ou até mesmo em razão da morte de animais.

O diagnóstico precoce da mastite permite minimizar perdas e estabelecer o protocolo de tratamento de forma econômica e eficiente, com maior índice de recuperação (RUEGG; REINEMANN, 2002;). O Califórnia Mastitis Test (CMT), o Wisconsin Mastitis Test (WMT), a caneca telada e a caneca de fundo preto são instrumentos de extrema utilidade, servindo como indicativos para o diagnóstico da mastite, porém, não são precisos, pois são métodos indiretos (SAAB, et al., 2014). Para um diagnóstico precoce, preciso e rápido da enfermidade faz-se necessário a utilização das ferramentas de precisão, dentre elas, o sistema automatizado para detecção de mastite (KASIKÇI et al., 2012).

O conceito de zootecnia de precisão está relacionado à redução otimizada das perdas, bem como, do incremento da aplicação e da gestão da qualidade do produto, dentro do processo gerenciado (NÄ̈̈S, 2011). A maximização dos índices produtivos alcançados e a minimização de custos de produção passam pela eficiência da relação entre as variáveis ao longo do período de produção. Dessa forma, o conceito de precisão tem uma relação muito íntima com a questão da eficiência produtiva em que os valores desejáveis devem ser atingidos com o menor grau de impacto financeiro possível (PINHEIRO, 2009).

Pelos motivos acima mencionados torna-se relevante discutir sobre os diferentes métodos automatizados de detecção de mastite, mostrando suas vantagens e limitações, com auxílio desses pode-se realizar precocemente o diagnóstico da mastite reduzindo as perdas econômicas na bovinocultura de leite.

\section{Importância Econômica da Mastite}

O impacto econômico da mastite vai além dos portões da fazenda, em que mudanças na composição do leite (redução em cálcio, fósforo, proteína e gordura, e aumento em sódio e cloro) reduzem sua qualidade (RUEGG; REINEMANN, 2002). Além disso, o antibiótico utilizado para tratar mastite é uma preocupação para a indústria, bem como para a saúde pública, em que a presença de resíduo de antibiótico no leite interfere no processo de manufatura de muitos produtos lácteos (queijo e outros produtos fermentáveis) (MARTINS et al., 2011), sendo que os sabores indesejáveis reduzem o valor dos produtos lácteos e a presença de resíduos de antibióticos, mesmo que baixa, podem causar problemas de saúde nos consumidores (TOZZETI et al., 2008).

Ribeiro (2006) afirmou que é possível diminuir os custos de produção quando se adotam medidas preventivas. Desta forma, abordagens são possíveis com relação ao manejo de doenças, na primeira, o produtor opta por agir preventivamente, de modo a reduzir o surgimento de doenças infecciosas e, consequentemente, seus gastos futuros com tratamento; e na segunda, o tratamento ocorre após o surgimento das doenças, consequentemente, mais dispendioso.

O prejuízo com a mastite no Brasil, conforme Fonseca e Santos (2000), chega a US\$184,00/vaca/ano. Lopes et al. (2012) relataram que o impacto econômico anual da mastite foi de $\mathrm{R} \$ 72.784,74$; $\mathrm{R} \$ 160.481,82$; e $\mathrm{R} \$ 277.411,25$, em rebanhos constituídos por 100 vacas da raça holandesa, com média diária de 20 litros de leite, por vaca em lactação, para frequências de mastites médias anuais de 1; 7 e $15 \%$, respectivamente. Tomando-se por referência uma vaca em lactação, variou de $\mathrm{R} \$ 727,85$ a $\mathrm{R} \$ 2.774,11$, em para frequências de mastites médias anuais de 1 e $15 \%$ de mastite clínica, respectivamente. Ribeiro (2006) observou que os gastos com diagnóstico preventivo foram, em média, $\mathrm{R} \$ 5,59$ por animal e com tratamento $\mathrm{R} \$ 20,69$, ou seja, se gasta cerca de quatro vezes mais com o tratamento do que com prevenção. Resultados semelhantes foram encontrados por Valente et al. (2012). Segundo Zanetti et al. (2013), o total de perdas causado pela incidência de mastite por um ano em lote de 60 animais do rebanho de vacas holandesas do Sistema Intensivo de Produção de Leite (SIPL) do campo experimental da Embrapa Gado de Leite em Coronel Pacheco - MG foi de R\$ 23.004,77, sendo R\$13.046,05 em decorrência do descarte de leite e R\$ 9.958,72 gastos com o tratamento; essas perdas representaram $6,94 \%$ da renda proveniente da venda do leite. Bar et al. (2008) relataram que o custo médio por vaca para se tratar uma mastite clínica é em torno de U\$ 71,00. Holanda; Madalena (2005) estimaram que os custos e perdas totais com mastite foram equivalentes a US\$ 126,00 por vaca em lactação por ano. Pinheiro (2009) relatou que cada caso de mastite não detectada precocemente, ou seja, ainda subclínica, produz um prejuízo de cerca de $240 €$ /lactação.

Mundialmente, a mastite é reconhecida como a doença mais dispendiosa das propriedades leiteiras. Philpot (1984) calculou que 70\% das perdas econômicas, devido à mastite subclínica, podem ser atribuídas à queda de produção, $8 \%$ ao descarte de leite contaminado, $8 \%$ à assistência veterinária e os $14 \%$ restantes, gastos com medicamentos, mão de obra, à diminuição do valor comercial e à reposição do plantel.

\section{Automação - Inovação Tecnológica na Pecuária Leiteira}

Para Pires e Bielschowsky (1978), a adoção da automação é um dos grandes momentos da história das inovações tecnológicas no segmento do leite. A mudança no perfil do produtor rural, para um modelo empresarial de gestão da propriedade, trouxe para a pecuária leiteira a necessidade de um controle maior de todas as etapas do processo produtivo, crescendo, desta forma, a demanda por sistemas informatizados e/ou automatizados. Segundo Costa (2001), um sistema automatizado permite monitorar e/ou controlar o funcionamento de um sistema físico de forma segura, rápida e automática.

Sistemas de automação têm grande potencial de uso na agropecuária, sendo utilizados na agricultura e zootecnia de precisão para automatizar processos, monitorar os sistemas, tornar a produção eficiente e reduzir perdas, podendo responder a situações de adversidade de forma inteligente, evitando que um problema se agrave (SILVA, 2007).

Um sistema de automação é composto por sensores 
capazes de coletar informações das mais diversas, transferi-las para um controlador conectado a um processador (computador) que armazena os dados, processa, gera os parâmetros de ação para os controladores e transforma os dados em informações práticas aos usuários (SILVA, 2003). Segundo
Gonçalves (2001), equipamentos que envolvem zootecnia de precisão podem ser empregados em diversas etapas do processo produtivo, desde a identificação de animais até o monitoramento de sistemas de produção e fornecimento de alimentos, conforme pode ser observado na Figura 1.

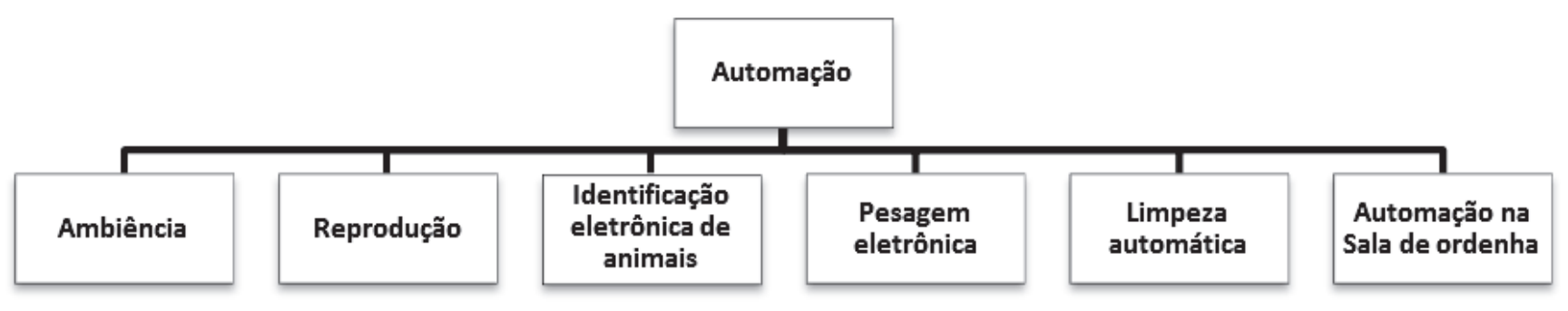

Figura 1: Áreas onde a automação pode interferir. Fonte: Botega et al. (2008)

O monitoramento visa a automatizar o registro de ocorrências num dado sistema, bem como alertar o produtor em caso de situações excepcionais. Existem inúmeros exemplos de sistemas de automação com os mais variados graus de complexidade, sendo que alguns pontos comuns os caracterizam. Assim, deve-se de alguma forma, perceber o ambiente que os cercam e atuar nesse ambiente de modo preciso; para isso são necessários os sensores e atuadores (FIALHO, 1999).

Sistemas de sensores constituem instrumentos úteis para garantir na exploração leiteira um controle da reprodução, da eficiência da alimentação, da qualidade do leite e da saúde do úbere (PINHEIRO, 2009).

\section{Mastite}

\section{Métodos Automatizados para o Diagnóstico de}

\section{Condutividade elétrica (CE)}

Condutividade elétrica é a propriedade que certas substâncias possuem de favorecerem, ou não, a passagem da corrente elétrica ou calorífera, variando de acordo com a natureza da substância; no leite, os íons são os principais componentes para se conduzir eletricidade (NEVILLE; JENSEN, 1995). Sistemas de transporte nas células secretoras da glândula mamária mantém a proporção de sódio-potássio no leite de aproximadamente 1:3, na qual, no fluido extracelular ou sangue, é de 30:1, sendo ainda que a concentração de cloreto no leite é muito menor do que no sangue. Os ductos mamários são impermeáveis aos íons, mas a mastite leva a uma mudança na permeabilidade capilar sanguínea, que resulta em uma diminuição da concentração de potássio no leite e aumento das concentrações de sódio e cloretos devido ao aumento da permeabilidade de capilares e a destruição dos sistemas de bombeamento de íon ativos (HAMANN; ZECCONI, 1998). Quando a vaca apresenta mastite ocorre aumento das concentrações de $\mathrm{Na}+$ e $\mathrm{Cl}$ - no leite, que tem como consequência aumento da $\mathrm{CE}$, desta forma, a corrente elétrica irá fluir mais facilmente por meio do leite com mastite do que num leite normal, devido ao alto conteúdo iônico (ZAFALON et al., 2005).

Como resultado das alterações de permeabilidade dos capilares sanguíneos as concentrações de íons no leite mudarão, uma vez que o leite é iso-osmótico como o sangue, as células secretoras da glândula mamária estabilizarão a pressão osmótica. Vários autores (FERRERO et al., 2014; HAMMER et al., 2012; KASIKÇI et al., 2012; NORBERG et al., 2004) determinam a CE para leite de vacas normais e com mastite clínica ou subclínica, onde a CE do leite proveniente de vacas saudáveis variam entre 4,0 a $5,0 \mathrm{mS} / \mathrm{cm}$ (SANTOS, 2002), sendo que os valores aumentam para 5,37 em casos subclínicos e para $6,73 \mathrm{mS} / \mathrm{cm}$ para casos clínicos de mastite (SANTOS, 2002). Sheldrake et al. (1983) encontraram valores de CE que variaram de 4,6; 5,8 e 6,5 respectivamente, para leites com CCS média de 158, 200 e 251 mil células/mL em vacas da raça Holandesa.

A unidade de medida da CE é o Siemens/metro e é calculado pelo quociente entre a intensidade da corrente e a tensão elétrica, em que o valor normal da $\mathrm{CE}$ do leite, a $25^{\circ}$ Celsius, oscila entre 4,0 e 5,5 miliSiemens $/ \mathrm{cm}(\mathrm{mS} / \mathrm{cm})$, normalmente a CE no leite normal é entre 4,0 e $5,0 \mathrm{mS}$ a $25^{\circ} \mathrm{C}$, entretanto, quando a $\mathrm{CE}$ do leite for maior que os valores de referência, sugere-se a possibilidade de um quadro de mastite clínica ou subclínica. Além disso, a CE aumenta com a temperatura da amostra de leite, então espera-se que a CE seja um pouco mais elevada quando é mensurada logo após a ordenha porque a temperatura do leite é cerca de $38^{\circ} \mathrm{C}$, quando deixa a cisterna da teta (HOGEVEEN et al, 2010). No leite a $\mathrm{CE}$ é determinada pela concentração de íons, sendo os mais importantes o sódio, o potássio e o cloreto. Quando um animal é acometido pela mastite, a concentração de potássio no leite diminui, enquanto as concetrações de íons sódio e e cloreto elevam-se devido ao aumento da permeabilidade dos capilares sanguíneos e à destruição dos sistemas de bombeamento iônico, conduzindo ao aumento da CE (WONG, 1988; NIELEN et al., 1992).

Como a mastite é um evento que ocorre no quarto do úbere, medições da $\mathrm{CE}$ a este nível podem dar a possibilidade de comparar os quartos do animal, aumentando assim a confiabilidade do teste. Estudos publicados (DE MOL; OUWELTJES; HOGEVEEN, 2001; NORBERG et al., 2004; KAMPHUIS et al., 2010; SUN et al., 2010) usam CE como diagnóstico de mastite, com uma grande variação de resultados de desempenho (HOGEVEEN, 2010).

Há muitos estudos sendo realizados sobre a utiliza- 
ção da CE para detecção de mastite (HAMANN; ZECCONI, 1998), sendo que Nielen et al. (1992) realizaram uma série de experimentos e encontraram resultados variados em 77 estudos conhecidos até 1992. A sensibilidade geral foi $66 \%$ com uma especificidade total de 94\%. Segundo Hogeveen (2010), para um desempenho ótimo para um sistema de detecção de mastite clínica esse deve oferecer, pelo menos, uma sensibilidade de $80 \%$ e uma especificidade de $99 \%$, em que o único método que se aproxima desses valores é o método de $\mathrm{CE}$.

Experiências com infecções induzidas mostram que a CE pode ser usada (sensibilidade de $100 \%$ ) para a detecção de mastite clínica antes dos sinais clínicos aparecerem (MILNER et al., 1996), no entanto, estes casos de mastite foram artificialmente induzidos, nas quais as medições foram feitas utilizando um aparelho portátil e não pelo equipamento em linha (KAMPHUIS et al., 2010). De Mol, Ouweltjes e Hogeveen (2001) descreveram estudos de campo com resultados ainda mais variados, nos quais sistemas de detecção de mastite em linha disponíveis comercialmente foram usados em quatro fazendas durante vários anos, com resultado do teste do software do fabricante. Apresentando variação da sensibilidade entre 18 e $36 \%$ e da especificidade entre 98,1 e 99,4\%.

Para mensuração da CE existem dois tipos de equipamentos, um aparelho portátil e um equipamento acoplado a ordenhadeira automatizada. No sistema acoplado a medição da CE ocorre a cada ordenha por meio de softwares, e esses dados são armazenados em computadores, sendo que quando há uma variação individual, um sinal de alerta é disparado, indicando o animal que pode estar com mastite (JANZEKOVIC, 2012).

O equipamento portátil tem a vantagem de poder ser utilizado em vários locais e ser de fácil utilização, entretanto, possui protocolos a serem seguidos, nos quais a Coleta de amostras homogeneizadas a partir da ordenha completa, calibragem do aparelho com solução padrão antes do início dos testes, e mensurações devem ser realizadas em temperatura ambiente (JANZEKOVIC, 2012).

Em nenhum dos trabalhos revisados obteve-se informações sobre a viabilidade econômica do uso da CE para diagnóstico de mastite; entretanto o método possui a vantagem de ser portátil, rápido e obter o resultado das análises na propriedade. Possui como desvantagem o aparecimento de falsos positivos, por isso, ainda é utilizado em conjunto com outros métodos (VINGER, 2009).

\section{Contagem de células somáticas (CCS)}

Células somáticas são todas as células presentes no leite, incluindo as células originárias da corrente sanguínea, como leucócitos, e as células provenientes da descamação do epitélio glandular secretor. Em sua maioria, os leucócitos são mais mobilizados da corrente sanguínea para o tecido mamário, mediante alterações na permeabilidade capilar (MARTINS et al., 2011). Na secreção láctea de vacas com infecção intramamária ocorre um aumento na quantidade de células de defesa, passando a predominar neutrófilos, seguidos por macrófagos, linfócitos e permanecendo inalterada a quantidade de células epiteliais (PHILPOT; NICKERSON, 1991). No momento em que a glândula mamária se torna infectada, um rápido fluxo de leucócitos polimorfonucleados são conduzidos à região, levando a um aumento da CCS (PAAPE, 1979).
O método de CCS automatizado baseia-se no princípio da leitura óptica. O brometo de etídio, que é um agente intercalante e que é utilizado como um marcador fluorescente, penetra e intercala com DNA nuclear, e o sinal fluorescente gerado é usado para estimar a CCS no leite (HOGEVEEN, 2010). Esse sistema permite a contagem das células somáticas para leite de vaca, cabra e ovelha obtendo resultados em menos de um minuto, além de ser um equipamento portátil que pesa $4 \mathrm{~kg}$ e funciona a pilhas com capacidade de armazenamento de até 750 medições (HOGEVEEN, 2010).

A coloração de células somáticas pode ser realizada utilizando-se metodologia indireta, como o CMT, e direta, quer seja por contagem microscópica ou contagem eletrônica, sendo um excelente indicador da saúde da glândula mamária e da qualidade do leite (SANTOS, 2002).

A microscopia direta é o método de referência para a determinação da CCS em leite cru, em que uma alíquota de leite $(0,01 \mathrm{~mL})$ é distribuída homogeneamente, em uma área delimitada $(1 \mathrm{~cm})$ na superfície de uma lâmina com o auxílio de uma pipeta automática calibrada. Após a secagem, as lâminas devem ser coradas com uma solução de azul de metileno $0,6 \%$ (corante de Newman-Lampert modificado por Lebowitz-Weber) e, em seguida, as células coradas são contadas por meio da observação em um microscópio óptico (MARSHALL, 1992).

Embora a análise pelo método de microscopia direta forneça informações essenciais sobre a condição da matéria-prima, trata-se de um procedimento que requer um trabalho intenso, com ampla variabilidade de interpretação entre diferentes observadores. Métodos clássicos de análises, como é o caso dessa técnica, que durante muitos anos foi referência na determinação do parâmetro exigido, são limitados por não terem sido concebidos para a análise em série de uma grande quantidade de amostras, necessitando de mão de obra excessiva que, devido ao seu custo cada vez maior, impede sua aplicação rentável (LEITE, 2006).

Diante dessas limitações, a CCS pode ser realizada em equipamentos eletrônicos, a exemplo do Somacount ${ }^{\circledR}$ (Bentley Instruments Incorporated ${ }^{\circledR}$ ) e Fossomatic ${ }^{\circledR}$ (Foss Eletric $^{\circledR}$, Hillerod, Dinamarca). Esses equipamentos são utilizados pela Rede Brasileira de Laboratórios de Controle da Qualidade do Leite - RBQL como alternativa para aperfeiçoar o controle leiteiro e a qualidade do leite (PAULA et al., 2004; FONSECA, 2005; LEITE, 2006).

$\mathrm{O}$ equipamento Somacount ${ }^{\circledR}$ baseia-se no princípio da citometria de fluxo. $\mathrm{Na}$ análise, uma alíquota da amostra é coletada pelo instrumento, aquecida a $67^{\circ} \mathrm{C}$ e levada a uma seringa contendo o corante tampão (brometo de etídio). Em seguida, $50 \mu \mathrm{L}$ da amostra são carreadas por um líquido para o interior do equipamento, ocorrendo a incidência de raio laser sobre a amostra. Os núcleos corados emitem fluorescência, a qual passa por uma série de filtros ópticos e lentes focalizadas em comprimentos de ondas apropriados e, é captada como pulso elétrico. Esse pulso é ampliado, filtrado eletronicamente e convertido em contagem de células somáticas (FONSECA, 2005; LEITE, 2006).

A importância de se diagnosticar vacas com mastite subclínica, e aparentemente saudáveis, pelo uso da CCS individual, é descobrir quais animais podem ser transmissores da mastite pela linha de ordenha ou pela mão do ordenhador. Esses animais além de serem focos de contaminações, con- 
tribuem pela baixa qualidade do leite e menor volume total produzido, o que reflete em perdas econômicas à propriedade (MOEINI et al., 2002).

Hogeveen (2010) mostrou que medir CCS individualizando os tetos, apresenta um melhor desempenho do que a detecção individual por animal, na qual se mistura o leite dos quatro tetos.

Os sensores que medem a CCS, baseados nos princípios do teste de CMT (WHYTE, 2005), ou baseados em espectrofotometria ótica, estão comercialmente disponíveis em sistemas de ordenha automáticos atualmente (LUSIS, 2010). O sensor baseado em princípios do CMT mais utilizado é o do processo da gel-formação, em que se estudou a combinação do uso do sensor de CCS juntamente com o sensor da condutividade elétrica. Observou-se que ao combinar as mensurações dos sensores de condutividade elétrica e da CCS, o desempenho do modelo da detecção melhorou $11 \%$ (KAMPHUIS et al., 2008).

De acordo com Hogeveen et al. (1994), a correlação entre condutividade elétrica e contagem de células somáticas não é alta, indicando que há mais fatores que influenciam a $\mathrm{CE}$, tais como a temperatura e o teor de gordura no leite. $\mathrm{O}$ uso da espectrofotometria de infravermelho (NIR) mostrou que é possível mensurar a CCS no leite cru (TSENKOVA, 1999). Além disso, a CCS é usada como uma importante ferramenta para o controle de mastite. Visando este diagnóstico precoce, um analisador de NIR tem sido estudado, porém ainda não está disponível pára comercialização (KATZ, 2007).

O método CCS possui como vantagens ser rápido e automatizado e possui como desvantagens o valor do equipamento, US\$ 7.000,00, e complexidade de uso, necessitando treinamento e capacitação (VIGUIER, 2009).

\section{Lactato desidrogenase}

A Lactato-desidrogenase (LDHA) é uma enzima que faz parte do processo glicolítico, encontrada no citoplasma de todas as células e tecidos do corpo dos bovinos, em que o resultado de suas reações enzimáticas pode ser considerado como diagnóstico de mastite (LARSEN, 2005). A LDHA é um indicador sensível de mastite como resultado da resposta imune do animal contra a infecção e alterações químicas da membrana celular (FRIGGENS; CHAGUNDA, 2007).

A atividade da LDHA é analisada por espectrofotometria, método descrito por Larsen (2005). A análise de sua atividade é um procedimento clássico. A oxidação do lactato é estimada devido a sua absorção aumentada ou, também, por meio da redução do piruvato, que pode apresentar absorção diminuída na espectrofotometria. Segundo Lombardi et al. (2000), a partir desses dados alcançados em laboratório pode-se suspeitar de mastite.

No uso da espectrofotometria deve-se ter cuidado, pois amostras de leite muito gordurosas, acima de $4,1 \%$, podem dispersar a luz, causando resultados falsos negativos. Porém, normalmente, o leite é opaco, possuindo uma solução coloidal de proteínas que irão se espalhar bem no equipamento e irão absorver a luz, excluindo a possibilidade de problemas sérios na espectrofotometria (BERGMEYER, 1995). Não obstante, as análises de LDHA de amostras de leite muito gordurosas já foram executadas usando a espectrofo- tometria, porém para esses casos, nas análises são realizadas um pré-tratamento das amostras, diminuindo a quantidade de gordura, para minimizar problemas com a dispersão da luminosidade (ZANK; SCHLATTERER, 1998). LDHA é um grande potencial para a detecção de mastite clínica (SUN, 2010). Segundo Chagunda (2006), um biosensor tem sido avaliado usando simultaneamente dados simulados e dados da propriedade, nos quais amostras de leite foram analisadas em um laboratório com resultados de bom desempenho, porém, apesar de estar disponível comercialmente seu desempenho não foi avaliado a campo (MAZERIS, 2010).

O método de LDHA possui como vantagem a rapidez e a possibilidade de diagnóstico da mastite cerca de 48 horas antes do aparecimento dos sintomas devido a grande sensibilidade das enzimas, entretanto apresenta grande desvantagem em função da necessidade de uma base laboratorial (VIGUIER, 2009). Nesta ampla revisão bibliográfica não foram encontrados referências sobre a viabilidade econômica do uso de LDHA no diagnóstico de mastite.

\section{Gestão pró-activa do estábulo - Herd Navigator ${ }^{\circledR}$}

O Herd Navigator ${ }^{\circledR}$ é um laboratório de análises que se instala na máquina de ordenha e permite determinar os parâmetros de progesterona, lactose desidrogenada, ureia e ß-hidroxibutirato no leite (PINHEIRO, 2009). Na Tabela 1 pode-se observar os parâmetros avaliados pelo equipamento.

Tabela 1: Parâmetros avaliados pelo Herd Navigator ${ }^{\circledR}$

\begin{tabular}{|c|c|c|}
\hline Área & $\begin{array}{c}\text { Parâmetro } \\
\text { analisado no } \\
\text { leite }\end{array}$ & $\begin{array}{l}\text { Detecção automá- } \\
\text { tica / na hora }\end{array}$ \\
\hline Reprodução & Progesterona & $\begin{array}{l}\text { Estro, estro silen- } \\
\text { cioso, gestação, } \\
\text { aborto e cistos }\end{array}$ \\
\hline Saúde do úbere & LDHA & $\begin{array}{l}\text { Mastite e mastite } \\
\text { subclínica }\end{array}$ \\
\hline $\begin{array}{l}\text { Balanço alimen- } \\
\text { tar e energético }\end{array}$ & $\begin{array}{l}\text { Ureia e BHB- } \beta \\
\text { hidroxibutirato }\end{array}$ & $\begin{array}{l}\text { Ração (proteína), } \\
\text { cetose, cetose sub- } \\
\text { clínica, desordens } \\
\text { metabólicas e se- } \\
\text { cundárias }\end{array}$ \\
\hline
\end{tabular}

Fonte: adaptado de Pinheiro (2009).

A amostra do leite chega automaticamente ao ponto de análise, desde a unidade de ordenha, sem intervenção do ordenhador. Posteriormente, esta é extraída mediante copo de recolhimento de amostra e é enviada à unidade de entrada das amostras por meio de uma tubagem, que é lavada posteriormente. Da unidade de entrada, a amostra é enviada ao laboratório à medida que ele fique disponível para a amostra seguinte (PINHEIRO, 2009).

O sistema trabalha realizando amostragem representativa do leite das vacas, individualmente, durante a ordenha, onde serão realizados exames nas amostras coletadas em cada quarto do úbere que estão conectados à ordenha robotizada. Todas as amostras são levadas intactas para o analisador automático localizado na sala de leite, onde as análises serão realizadas pelo equipamento com posterior medição dos parâmetros encontrados (ASMUSSEN, 2010). 
Os valores encontrados a partir do analisador automático passam ao computador, diretamente para o programa instalado, para que o produtor tenha os valores disponíveis e o biomodelo aumente a sua base de dados e tome a decisão sobre quais animais precisam ser tratados para mastite e quando deve ser feita uma nova análise (PINHEIRO, 2009).

As análises do Herd Navigator ${ }^{\circledR}$ medem, automaticamente, a enzima Lacto desidrogenase (LDHA) no leite. Essa enzima está diretamente relacionada com a quantidade de células somáticas e, por conseguinte, com a presença de mastites. Como os valores de LDHA aumentam rapidamente quando começa uma infecção, o Herd Navigator ${ }^{\circledR}$ é capaz de detectar o início de uma mastite, dias antes dela aparecer (ASMUSSEN, 2010).

A análise é decidida e feita de forma automática, selecionando as vacas que se encontram nos momentos de maior risco, e identificando aquelas que devem ser tratadas ou, pelo menos, verificadas, tomando a iniciativa para solucionar o problema antes que esse apareça (MAZERIS, 2010).

Na gestão pró-activa do estábulo - Herd Navigator ${ }^{\circledR}$ a totalidade das informações são baseadas em mão de obra de países desenvolvidos, como Estados Unidos e Canadá, onde acredita-se que seja viável economicamente em até quatro anos pós-implantação da automatização (VIGUIER, 2009), entretanto requer estudos de viabilidade econômica. Em países como o Brasil, onde a mão de obra é assalariada, deve-se aprofundar os estudos para se saber se a automação a esse nível nas propriedades rurais brasileiras é viável economicamente. Estudos com médias de rebanhos europeus usando esse método mostraram que é possível aumentar o ganho entre 250 e 300 euros por vaca/ano (MAZERIS, 2010).

\section{Coloração}

A avaliação direta, das características físicas do leite anormal, provavelmente oferecerá melhores resultados de detecção, do que uma aferição de um indicador indireto da mastite, onde uma das características físicas do leite que podem ser avaliadas é sua cor (HOGEVEEN, 2010).

Segundo Hogeveen (2010) o princípio do método é baseado na espectrofotometria, em que a presença de sensores, de acordo com o reflexo de luz gerada por um LED, determina a opacidade da amostra, sendo que quanto mais branco o leite, mais luz é refletida. Neste método três diferentes comprimentos de onda são medidos pelo sensor, vermelho, verde e azul. Além disso, outra versão de um sensor de cor baseia-se na transmissão de luz e não na reflexão de luz (HOGEVEEN, 2010).

A coloração mostrou ser um bom método para detectar o leite anormal sob circunstâncias de laboratório (OUWELTJES; HOGEVEEN, 2001), em que as amostras de leite retiradas a partir do exame de oito vacas com mastite clínica e diluídas gradualmente foram usadas para avaliar o sensor da medida de cor, sendo que as anormalidades devido a mastite clínica e a presença de sangue no leite resultaram nos valores da cor claramente diferentes daqueles do leite normal (HOGEVEEN, 2010).

Entretanto, os primeiros resultados de um estudo de campo em duas fazendas mostraram resultados desfavoráveis em circunstâncias práticas, pois quando se relaciona informações de cores encontra-se muitos resultados ambíguos,nos quais o maior sucesso de sistemas óticos para detectar o leite mastítico está relacionado com a detecção de sangue no leite (ESPADA; VIJVERBERG, 2002). Esses autores também descreveram sobre um sensor ótico emissor de luz com algoritmos que diferencia o leite da cor média, porém só se mostrou eficaz quando se encontrou sangue, colostro ou algumas outras anormalidades do leite.

Em estudos sob condições de laboratório, utilizaram amostras de leite homogeneizado de oito vacas com mastite clínica e o potencial para detectar mastite por meio de medições de cor foi estimado, assim as amostras de leite dos quartos suspeitos de todas as oito vacas positivas apresentaram valores de cor mais baixos do que o leite homogeneizado (OUWELTJES; HOGEVEEN, 2001).

Song et al. (2010) mostraram que o potencial das medições de cor ajudam o diagnóstico, mas podem ter erros, por isso, deve-se utilizá-los em combinação com outros sensores.

O método de coloração é o mais prático de todos, porém, é o com menor especificidade, entretanto Sensores para o método estão sendo desenvolvidos, entretanto ainda sem utilidade prática (HOGEVEEN, 2010).

A coloração possui como vantagem a facilidade de uso, pois pode ser realizada no momento da ordenha, contudo apresenta a desvantagem de ser um método subjetivo, além de ser necessária a confirmação da mastite através de outros métodos com mais especificidade e mais sensibilidade (VIGUIER, 2009).

Mesmo este método sendo simples, não se encontrou, nesta ampla revisão de literatura, estudos de viabilidade econômica para o uso da coloração objetivando o diagnóstico de mastite.

\section{Homogeneidade}

O termo mastite refere-se a inflamação das glândulas mamárias, qualquer que seja a causa. Caracteriza-se por alterações físicas, químicas e geralmente bacteriológicas do leite, e por alterações patológicas do tecido glandular (BLOOD; HENDERSON, 1974) A detecção visual da mastite clínica pelo produtor rural ocorre na verificação dos primeiros jatos de leite, antes de ordenhar. Dessa forma, quando o leite não é branco ou homogêneo, sugere-se que a vaca possa estar com mastite clínica (DOOD, 1983). A homogeneidade do leite pode, consequentemente, ser um parâmetro interessante para a detecção de mastite, quando, por exemplo, se processar o material através de espectrofotometria de onda (DALGLEISH; HALLETT, 1995; ELOFSSON et al., 1996).

O método da homogeneidade, atualmente, consiste na visualização do leite anormal durante a ordenha. Estudos apontam que o uso de sensores pode auxiliar na detecção prévia de mastite a partir do momento que se conseguir avaliar a homogeneidade do leite previamente (SUN, 2010).

Um sensor para medir a homogeneidade do leite foi sugerido (MAASSEN-FRANCKE, 2004), mas nenhuma informação está disponível além do trabalho de desenvolvimento nesse tipo específico de sensor (HOGEVEEN, 2010).

A homogeneidade, assim como o método da coloração, é prático de ser realizado, porém apresenta baixa especificidade e sensibilidade. Dessa forma, perde credibilidade 
caso seja utilizado sem o acompanhamento de outros métodos de detecção (HOGEVEEN, 2010).

Nesta ampla revisão da literatura não foram encontrados estudos de viabilidade econômica para o uso do método de homogeneidade objetivando o diagnóstico de mastite.

\section{Considerações finais}

Apesar dos grandes avanços na bovinocultura, existe a possibilidade de melhorar a eficiência de produção. No entanto, para que isso ocorra, é necessário usar tecnologias mais avançadas que diminuam as perdas e controlem o sistema de produção de maneira mais rígida. Assim, na zootecnia de precisão, a informação passa a ser um recurso valioso, que permite otimizar o uso de insumos no sistema de produção, no qual o uso de sistemas de automação no diagnóstico de mastite permite o controle precoce da enfermidade, diminuindo os prejuízos econômicos.

Dentre os métodos de automação, os mais estudados e mais aplicados são os que mensuram a condutividade elétrica juntamente com a CCS. O estudo permitiu observar que ainda existe a necessidade de se utilizar testes complementares, pois a maioria dos métodos não possuem a especificidade e a sensibilidade necessária para confirmação de diagnóstico precoce da mastite, excetuando-se o Herd Navigator $^{\circledR}$; pois esse possui um avançado modelo biométrico automatizado.

Neste trabalho de revisão não foi encontrado nenhuma citação quanto à viabilidade econômica da utilização de nenhum dos métodos automatizados utilizados para a detecção de mastite, apresentando apenas alguns valores de implantação do equipamento. Esse é um fator que precisa ser estudado, pois em não se deve recomendar a implantação de métodos sem conhecimento da viabilidade econômica.

\section{Referências}

ASMUSSEN, T. Herd Navigator - Real time herd management, or "How to benefit from frequent measurements!” In: ICAR REFERENCE LABORATORY NETWORK MEETING, 5, 2010, Riga. Proceedings... Riga: ICAR, 2010. v.1, p. 104-107.

BAR, D. et al. The cost of generic clinical mastitis in dairy cows as estimated by using dynamic programming. Journal of Dairy Science, Itahaca, v. 91, n. 6, p. 2205-2214, 2008.

BERGMEYER, H. U. Methods of Enzymatic Analysis, v. 3, Weinheim: VCH Verlagsgeschellschaft mbH, 1995. p. 118-138.

BLOOD, D. C.; HENDERSON, J. A. Medicina Veterinária, Guanabara Koogan, $4^{\circ}$ Edição, Rio de Janeiro. 1978, p. 225-230

BOTEGA, J. V. L. et al. Diagnóstico da automação na produção leiteira. Ciência Agrotécnica, Lavras, v. 32, n. 2, p. 635-639, 2008.

CHAGUNDA, M. G. G. et al. Model for detection of individual cow mastitis based on an indicator measured in milk. Journal of Dairy Science, Tjele, v. 89, n. 11, p. 29802998, 2006.

COELHO, L. B. et al. A estratégia de desenvolvimento regional Sustentável da agência do Banco do Brasil em Cantagalo/PR - um estudo de caso sobre bovinocultura leiteira. In: CONGRESSO INTERNACIONAL DE ADMINISTRAÇÃO, 14., 2013, Recife. Anais.. Recife: UNISSAU, 2013, v.2, p.18-22.

\section{COSTA, P. J. A. Automação na Pecuária Leiteira.}

Piracicaba, 2001. Folheto Técnico, n. 2, PROJEPEC, 16 p.

DALGLEISH, D. G.; HALLETT, F. R. Dynamic light scattering-Applications to food systems. Food Research Internacional, Ontario, v.28, n.3, p.181-193, 1995.

DE LAVAL. Herd Navigator. Disponível em: $<$ http://www. herdnavigator.com/pages/id33.asp $>$. Acesso em: $01 \mathrm{fev}$. 2014.

DE MOL, R. M.; OUWELTJES, W. Detection model for mastitis in cows milked in an automatic milking system.

Preventive Veterinary Medicine, Wageningen, v.49, n.1, p.71-82, 2001.

DOOD, F. H. Mastitis progress on control. Journal of Dairy Science, Shinfield, v. 66, n.8, p. 1773-1780, 1983.

ELOFSSON, U. M.; DEJMEK, P.; PAULSSON, M. A. Heat-induced aggregation of beta lactoglobulin studied by dynamic light scattering. International Dairy Journal, Lund, v.6, n.4, p.343-357, 1996.

ESPADA, E., VIJVERBERG, H. Milk colour analysis as a tool for the detection of abnormal milk. In: NORTH AMERICA CONFERENCE ROBOTIC MILKING, 1. , 2010, Toronto. Proceedings... Toronto: OMAFRA, 2010, v. 2. p. 97-101.

FERRERO, F. J. et al. Screening method for early detection of mastitis in cows. Measurement, Oviedo, v. 47, n. 1, p. 855-860, 2014.

FIALHO, F. B. Modernização no controle da produção de suínos: zootecnia de precisão. In: AMBIÊNCIA E QUALIDADE NA PRODUÇÃO INDUSTRIAL DE SUÍNOS, 3., 1999, Piracicaba. Anais... Piracicaba: FEALQ, 1999, v. 2, 246 p.

FONSECA, L. F. L.; SANTOS, M. V. Qualidade do leite e controle de mastite. São Paulo: Lemos Editora, 2000. 175 p.

FONSECA, C. S. P. Qualidade do leite cru de tanques refrigeradores de Minas Gerais. Belo Horizonte, 2005. 62 f. Dissertação (Mestrado em Medicina Veterinária) - Escola de Veterinária, Universidade Federal de Minas Gerais.

FRIGGENS, N. C.; CHAGUNDA, M. G. G. Estimating degree of mastitis from time-series measurements in 
milk: A test of a model based on lactate dehydrogenase measurements. Journal of Dairy Science, Tjele, v. 90, n. 12, p. 5415-5427, 2007.

GONÇAlVES, A. C. Automação na Pecuária. Brasília, 2001. Manual Técnico, n. 1. Projetos e Consultoria Agropecuária, p. 26.

HAMANN, J.; ZECCONI, A. Evaluation of the electrical conductivity of milk as a mastitis indicator. Brussels, 1998. Bulletin of the IDF No. 334/1998. IDF, p. 334.

HAMMER, J. F. et al. Quarter-milking-, quarter-, udderand lactation-level risk factors and indicators for clinical mastitis during lactation in pasture-fed dairy cows managed in an automatic milking system. Australian Veterinary Journal, Queensland, v. 90, n. 5, p. 167-174, 2012.

HOGEVEEN, H. et al. Knowledge representation methods for dairy decision-support systems. Journal of Dairy Science, Utrecht, v. 77, n. 12, .p. 3704-3715, 1994.

HOGEVEEN, H. et al. Sensors and Clinical Mastitis - The Quest for the Perfect Alert. Sensors, Wageningen, v. 10, n. 2, p. 7991-8009, 2010.

HOLANDA, E. V. J., MADALENA, Impacto econômico da mastite em seis fazendas de Araxá - Minas Gerais, Brasil. Archivos latinoamericanos de producción animal, Petrolina, v. 13, n. 2, p. 63-69, 2005.

IBGE. Instituto Brasileiro de Geografia e Estatística. Censo Agropecuário. Disponível em: <http://www.ibge.gov.br/ home/estatistica/economia/agropecuaria/censoagro/default. shtm>. Acesso em 17 de jan. 2014.

JANZEKOVIC, M. et al. Mastitis detection based in electric conductivity of milk. Journal of Achievements in Materials and Manufacturing Engineering, Slivnica, v. 34, n. 1. p. 39-46, 2012.

KAMPHUIS, C. et al. Decision-tree induction to detect clinical mastitis with automatic milking. Computer Electronic Agriculture, Utrecht, v. 70, n. 1, p. 60-68, 2010.

KAMPHUIS, C. et al. Automatic detection of clinical mastitis is improved by in-line monitoring of somatic cell count Journal of Dairy Science, Utrecht, v. 91, n. 12, p. 4560-4570, 2008.

KAŞIKÇI, G. et al. Relations between electrical conductivity, somatic cell count, California mastitis test and some quality parameters in the diagnosis of subclinical mastitis in dairy cows. Turkish Journal of Veterinary \& Animal Science, Istambul, v. 36, n. 1, p. 49-55, 2012.

KATZ, G. et al. Current and near term technologies for automated recording of animal data for precision dairy farming. Journal Animal Science, Savoy, v. 90, n. 1, p. 377-377, 2007.
LARSEN, T. Determination of lactate dehydrogenase (LDH) activity in milk by a fluorometric assay. Journal of Dairy Research, Tjele, v. 72, n. 2, p. 209-216, 2005.

LEITE, M. O. Fatores interferentes na análise eletrônica da qualidade do leite cru conservado com azidiol líquido, azidiol comprimido e bronopol. Belo Horizonte, 2006. 92 f. Tese (Doutorado em Ciência Animal) - Escola de Veterinária, Universidade Federal de Minas Gerais.

LOMBARDI, P. et al. Buffalo-milkenzyme levels, their sensitivity to heat inactivation, and their possible use as markers for pasteurization. Journal of Food Protection, Napoli, v. 63, n. 7, p. 970-973, 2000.

LOPES, M. A. et al. Avaliação do impacto econômico da mastite em rebanhos bovinos leiteiros. Arquivos do Instituto Biológico, Lavras, v. 79, n. 4, p. 64-79, 2012.

LUSIS, I. et al. Effectiveness of Somatic Cell Count Determination in the Milking Robots. In: Conference Engineering for Rural Development, 27., 2010, Latvia. Proceedings.. Jelgava. Latvia University of Agriculture, 2010. v. 2, p. 112-116.

MAASSEN-FRANCKE, B. et al. A Method to detect flakes and clots in milk in automatic milking systems. In: MEIJERING, A. Automatic Milking, a better understanding. Wageningen: Wageningen Academic Publishers. 2004. p. 251- 290 .

MARTINS, P. F.; ANDRADE, H. V. Identificação de resíduos de antibióticos na recepção de leite cru prébeneficiado como perigo potencial para implantação do plano APPCC em laticínios. FAZU em Revista, Uberaba, v. 4, n. 8, p. 108-114, 2011.

McDOUGALL, S. et al. Relationship among somatic cell count, California mastitis test, impedance and bacteriological status of milk in goats and sheep in early lactation. Small Ruminant Research, Morrinsville, v. 40, n. 3, p. $245-254,2001$.

MARSHALL, R. T. Standard methods for the examination of dairy products. Baltimore. American Public Health Association. 1992. 546 p.

MAZERIS, F. De Laval Herd Navigator: Proactive Herd Management. In: FIRST NORTH AMERICA CONFERENCE ROBOTIC MILKING, 1., 2010, Toronto. Proceedings... Toronto: OMAFRA, 2010. v. 3, p. 114-117.

MILNER, P. K. L. et al. Detection of clinical mastitis by changes in electrical conductivity of foremilk before visible changes in milk. Journal Dairy Science, Berkshire, v. 79, n. 1, p. 83-97, 1996.

MOEINI, M. M. et al. High bacteria count in milk and it's economic loss. IN: WORLD BUIATRICS CONGRESS, 11., 2002, Hannover. Abstracts... Hannover: WBC 2002, v.2, p. 9-10. 
NÄÄS, I. A. Uso de técnicas de precisão na produção animal. Revista Brasileira de Zootecnia, Dourados, v.40, n.1(supl. especial), p.358-364, 2011.

NEVILLE, M. C.; JENSEN, R. G. The physical properties of human and bovine milks. San Diego: Academic Press, 1995. $85 \mathrm{p}$.

NICKERSON, S. C. O Papel da Terapia no Controle da Mastite. In: $2^{\circ}$ CONGRESSO PANAMERICANO DE QUALIDADE DO LEITE E CONTROLE DE MASTITE. 24., 2002, Ribeirão Preto. Anais...Ribeirão Preto: FEPALE, 2002. v. 2. p. 85-98.

NIELEN, M. et al. Electrical conductivity of milk Measurement, modifiers and meta analysis of mastitis detection performance. Journal Dairy Science, Utrecht, v. 75, n. 2, p. 606-614, 1992.

NORBERG, E. et al. Electrical conductivity of milk: Ability to predict mastitis status. Journal Dairy Science, Tjele, v. 87, n. 4, p. 1099-1107, 2004

OUWELTJES, W.; HOGEVEEN, H.. 2001. Detecting abnormal milk through colour measuring. In: 40TH NATIONAL MASTITIS COUNCIL ANNUAL MEETING, 3., 2001, Reno. Proceedings... Reno: NMC, 2001, v. 1, p. 217-219

PAAPE, M. J. et al. Leukocytes second line of defense against invading mastitis pathogens. Journal of Dairy Science, Beltsville, v. 62, n. 1, p. 135-153, 1979.

PAULA, M. C. et al. Contagem de células somáticas em amostras de leite. Revista Brasileira de Zootecnia, Maringá, v. 33, n. 5, p.1303-1308, 2004

PHILPOT, W. N.; NICKERSON, S. C. Mastitis: Counter Attack. A strategy to combat mastitis. Illinois: Babson Brothers Co., 1991. 150 p.

PHILPOT, W. N. Economics of mastitis control. In: SYMPOSIUM ON MASTITIS. VETERINARY CLINICS OF NORTH AMERICA, 9., 1984, Chicago. Proceedings: Chicago: Veterinary Clinics of North America, v. 6, p. 233245

PINHEIRO, C., PINHEIRO, A. Inovação e tecnologia na formação agrícola. Lisboa, 2009. Manual Técnico. 150 p

PIRES, E.; BIELSCHOWSKY, R. A. Dois estudos sobre tecnologia de alimentos. Rio de Janeiro, 1978. Boletim Técnico IPEA/INPES, 47 p.

RADOSTITIS, O. M. et al. Um tratado de doenças dos bovinos, ovinos, suínos, caprinos e equinos. Rio de Janeiro: Guanabara Koogan, 2002, p.1737.

REBHUN, W. C. Doenças do Gado Leiteiro. São Paulo. Roca, 2000. p. 377.
RIBEIRO, A. C. C. L. Controle sanitário dos rebanhos de leite. Informação técnica para o produtor de leite. Juiz de Fora, 2006. Circular Técnica, n. 4, Embrapa Gado de Leite, $45 \mathrm{p}$

RUEGG, P. L.; REINEMANN, D.J. Milk quality and mastitis tests. Bovine practitioner, v. 36, n. 1, p. 41-55, 2002.

SAAB, A. B. et al. Prevalência e etiologia da mastite bovina na região de Nova Tebas, Paraná. Semina: Ciências Agrárias, Londrina, v. 35, n. 2, p. 835-844, 2014.

SANTOS, M. V. Efeitos da mastite sobre a qualidade do leite e dos derivados lácteos. In: CONGRESSO PANAMERICANO DE QUALIDADE DO LEITE E CONTROLE DE MASTITE, 10., 2002, Ribeirão Preto. Anais... Ribeirão Preto: Instituto Fernando Costa, v. 2, p. 179-188.

SHELDRAKE, R. F. et al. Somatic cell count, electrical onductivity, and senun albumin concentration for detecting bovine mastitis. Journal of Dairy Science, Glenfield, v. 66, n. 3, p.548-555, 1983.

SILVA, I. J. O. Automação dos sistemas para aumento do conforto animal. Pirassununga, 2003. Folheto Técnico, NUPEA - ESALQ - USP.

SILVA, K. O. et al. Medidas do ambiente acústico em creche de suínos. Revista Brasileira de Engenharia Agrícola e Ambiental, Campina Grande, v. 11, n. 3, p. 339344, 2007.

SONG, X. et al. New model to detect clinical mastitis in Astronaut A3 next milking robot. In THE FIRST NORTH AMERICAN CONFERENCE ON PRECISION DAIRY MANAGEMENT, 1., 2010, Toronto, Proceedings: Toronto: OMAFRA, 2010, p. 2689-2693.

SUN, Z. B. et al. Detection of mastitis and its stage of progression by automatic milking systems using artificial neural networks. Journal of Dairy Research, Hamilton, v. 77, n. 2, p. 168-175, 2010.

TOZZETI, D. S. et al. Prevenção, controle e tratamento das mastites Bovinas - revisão de literatura. Revista Científica Eletrônica de Medicina Veterinária, Garça, v. 10, ano VI, p. 47-53, 2008.

TSENKOVA, R. et al. Near-infrared spectroscopy for dairy management: Measurement of unhomogenized milk composition. Journal of Dairy Science, Kobe, v. 82, n. 11, p. 2344-2351, 1999.

USDA. United States Department of Agriculture. Dairy: World Markets and Trad/Ranking of production. Disponível em: <http://www.usda.gov/wps/portal/usda/usdahome>. Acesso em 10 de fev. 2014

VALENTE, L. C. M. et al. Relação entre gastos preventivos 
e com tratamento: levantamento da situação em fazendas produtoras de leite de Minas Gerais, Brasil. Revista

Brasileira de Zootecnia. Niterói, v. 41, n. 1, p. 43-49, 2012.

VIGUIER, C. et al. Mastitis detection: Current trends and future perspectives. Trends Biotech, Dublin, v. 27, n. 8, p. 486-493, 2009.

WHYTE, D. et al. Chemical and rheological aspects of gel formation in the California Mastitis Test. Journal of Dairy Research, Hamilton, v.72, n. 1, p. 115 -121, 2005.

WONG, N. P. Physical proprieties of milk. New York: Van Nostrand Reinhold Co., 1988. 75 p.

ZAFALON, L. F. et al. Comportamento da condutividade elétrica e do conteúdo de cloretos do leite como métodos auxiliares de diagnóstico na mamite subclínica bovina.

Pesquisa Veterinária Brasileira, Nova Odessa, v. 25, n. 3, p. 159-163, 2005.

ZANETTI, L. A. P. et al. Impacto econômico da mastite clínica em rebanho da raça Holandesa no estado de Minas Gerais In: XII CONGRESSO INTERNACIONAL DO LEITE, 1., 2013, Porto Velho. Anais... Porto Velho: CNPGL, 2013, p.74-76.

ZANK, W.; SCHLATTERER, B. Assesment of subacute mammary inflammation by soluble biomarkers in comparison to somatic cells counts in quarter milk samples from dairy cows. Journal of Medicine Veterinary, Postdam, v.45, n. 10, p.41-51, 1998.

Recebido em: 22/04/2014 Aceito em: 17/12/2014 